\title{
The Atmospheric Circulation and Arctic Meteorology
}

\section{F. KENNETH HARE ${ }^{1}$}

In a sense this title contains a fallacy. Meteorology is the most global of all sciences in outlook, and it can be argued that there is no longer any such thing as arctic meteorology, at least in the free atmosphere. Fifteen years ago this was not so. We knew so little of the atmospheric circulation near the pole that it was legitimate to use the title, as I did when in 1954 I founded the Arctic Meteorology Research Group at McGill University (around a program of research transferred from the University of California at Los Angeles). The purpose of our research, and of a sister group at the University of Washington under R. J. Reed, was to bring an understanding of the role of the Arctic into the mainstream of meteorological knowledge. This has now been achieved, and the title is hence anachronistic.

Although it is no longer valid to talk of a specifically arctic meteorology, it is still true that the Arctic plays a special role in the planetary climate, in at least three domains.

At the ice/atmosphere interface over the Arctic Ocean and Greenland the very special energy régime is crucial to the present global climate. This régime has been the special interest of a group of meteorologists including F. I. Badgley, M. I. Budyko, Y. P. Doronin, J. O. Fletcher, M. K. Gavrilova, M. S. Marshunova, L. R. Rakipova, S. Orvig and E. Vowinckel. Norbert Untersteiner of the University of Washington, who has made major contributions to this study also reported at the Symposium, (see pp. 195-99), and as I have elsewhere (Hare 1968) summarized the status of the work, I shall make no attempt to add to what Dr. Untersteiner has said.

In the troposphere the work of Reed's group, of the Arctic Forecast Team at Edmonton (Canadian Meteorological Service), and of C. V. Wilson and others at McGill has shown that a distinctive arctic synoptic régime can be defined. This régime extends into the lower stratosphere up to $20 \mathrm{~km}$. (15 km. in summer). In the stratosphere and lower mesosphere it has been demonstrated (for review see Hare and Boville 1965) that the annual cycle is also highly distinctive, though not necessarily independent of the layers below.

I shall briefly review the advances made in this fifteen-year period in our knowledge of the tropospheric and stratospheric circulations. Dynamic meteorology is not a field where a facility like the U.S. Naval Arctic Research Laboratory can offer much help, since research depends on global data-gathering by analysis centres elsewhere. Nevertheless the surface observations from the drifting ice stations, and from radiosonde ascents made at some of these stations, are in the highest degree relevant. Point Barrow has thus at least a strong kinship with the work I am describing.

1Department of Geography, University of Toronto, Toronto, Ontario, Canada. 


\section{TROPOSPHERIC CIRCULATION}

Synoptic analysis over the north polar region became a practical possibility in the early 1950's, when the newly established surface and radiosonde stations in arctic Canada, Alaska and Greenland were joined by the various temporary drifting stations over the Arctic Ocean. Together with the longer established stations in arctic Scandinavia (including Svalbard and Jan Mayen) and the Soviet Union, these stations have created a thin but fairly adequate basis for analysis of the circulation up to $23 \mathrm{~km}$. (30-mb.), and less adequately to $30 \mathrm{~km}$. (10-mb.). More recently meteorological rocket soundings from a few stations have enabled us to get a rough picture to $60 \mathrm{~km}$., in the lower mesosphere.

Throughout the year the basic circulation of the troposphere above $1.5 \mathrm{~km}$. (or $850-\mathrm{mb}$.) consists of the familiar circumpolar westerly vortex. In summer (Fig. 1) the westerlies extend into arctic latitudes, but at other seasons (Fig. 2) the Arctic is covered by a cold barotropic core lacking organized circumpolar motion, and often containing one or two closed cold lows. Maximum velocities in this westerly ring and in the cold lows are at about 7 to $10 \mathrm{~km}$. Above this level, zonal circulation decreases. In winter, however, as the polar-night westerlies of

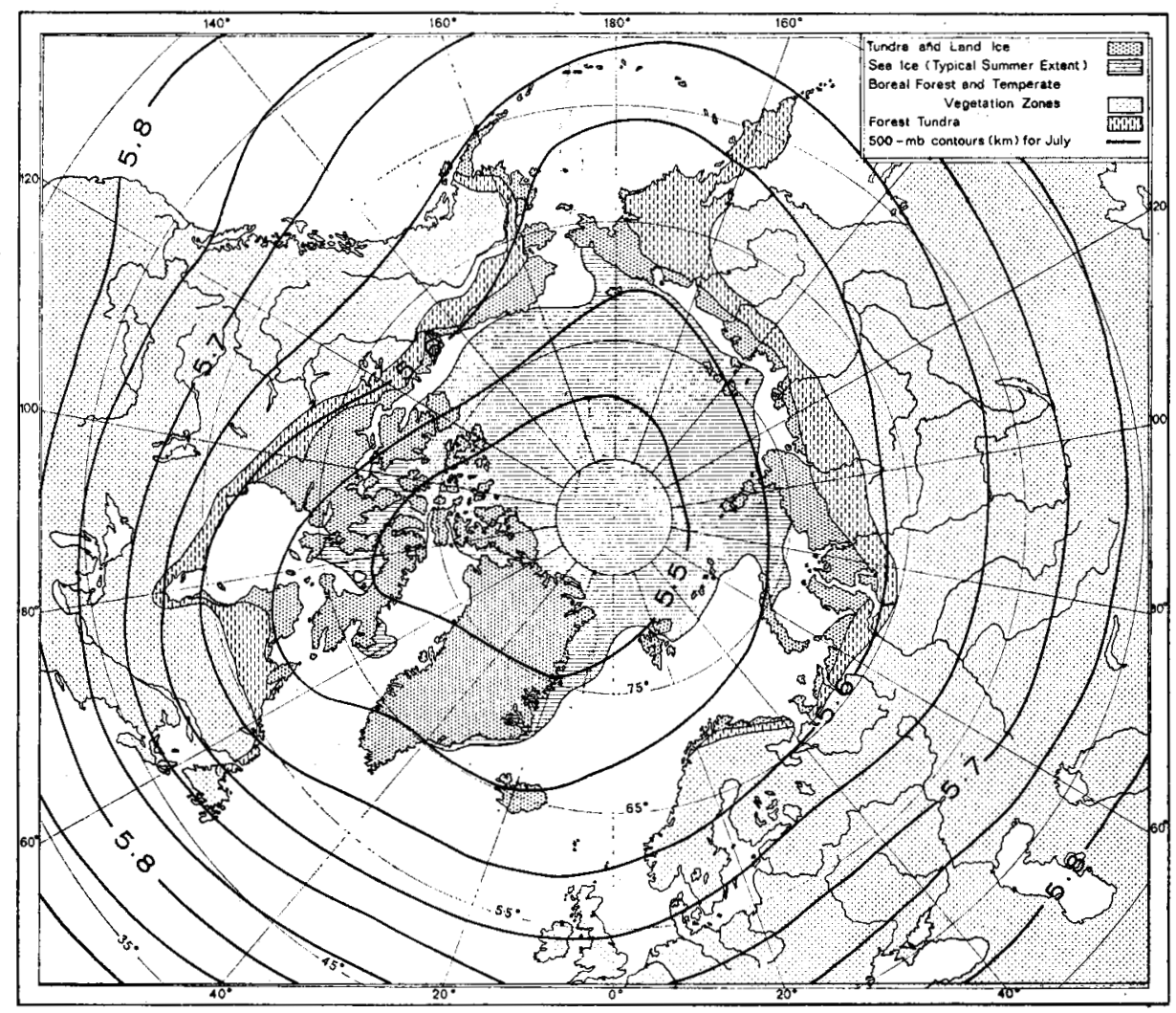

FIG. 1. Mean topography of 500-mb surface $(\mathrm{km})$ and related physical distributions for July. Contours are streamlines of resultant winds. 


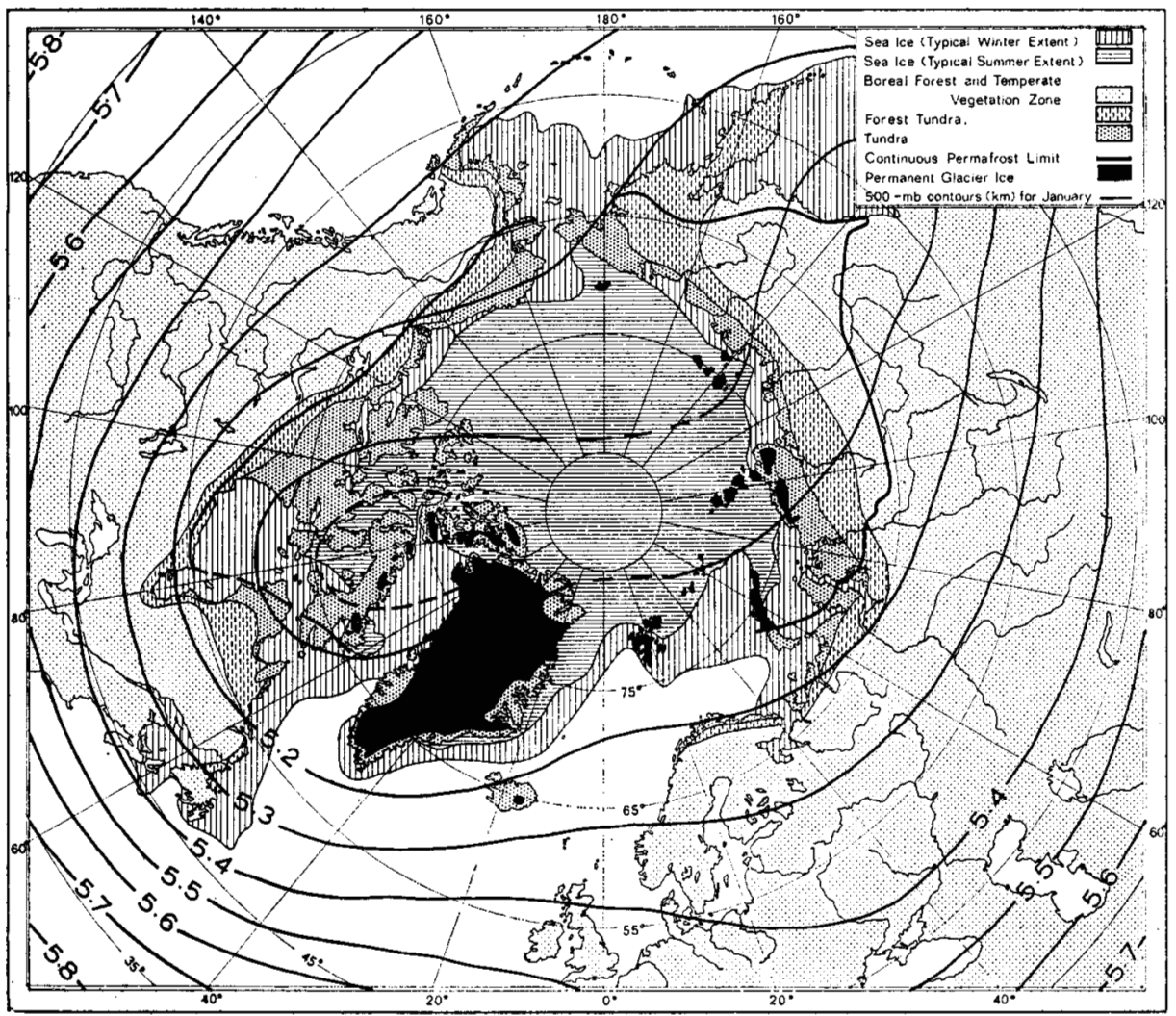

FIG. 2 Mean topography of $500-\mathrm{mb}$ surface $(\mathrm{km})$ and related physical distributions for January.

the stratosphere are entered, westerly components tend to increase again as low as $15 \mathrm{~km}$. In summer westerly flow is rarely detectable above $15 \mathrm{~km}$.

The northern part of the westerly current is strongly baroclinic and one can usually detect an arctic jet-stream and an arctic front within it. This front lies, on the average, across Alaska at all seasons, whereas over Eurasia and North America it undergoes strong seasonal shifts. In summer it lies close to the arctic tree-line, but in winter it moves south to the deep continental interiors. In North America it is then close to the southern limit of the Boreal Forest formation (Bryson 1966; Hare 1968). The complexity of the land/sea distribution in arctic Eurasia makes a surface location difficult between $60^{\circ} \mathrm{W}$. and $40^{\circ} \mathrm{E}$. In mid- and upper-troposphere, however, the arctic jet maximum can often be observed not far from the $5.4 \mathrm{~km}$. contour for the $500-\mathrm{mb}$. surface even in those longitudes.

It has been usual to associate this frontal jet-stream system with surface temperature contrasts and frontogenesis. At times, especially in summer, the net radiation field is indeed such as to create airmass contrasts (Fig. 3) near the line of the front (Reed and Kunkel 1960). But the baroclinity is strongest in the upper troposphere, and it is very likely that the arctic front is primarily the product of horizontal eddy-mixing processes tending to produce homogeneity over 
the inner Arctic, as originally proposed by Flohn (1952). If this is so, then the position of the front and jet reflects large-scale hemispheric dynamics rather than local surface differences. The arctic jet is strongly affected by standing circumpolar wave number 2 (Van Mieghem 1961), which has maximum amplitude (at $500-\mathrm{mb}$.) in about $60 \mathrm{~N}$., and which has a strong seasonal phase shift reflecting hemispheric heating inequalities.

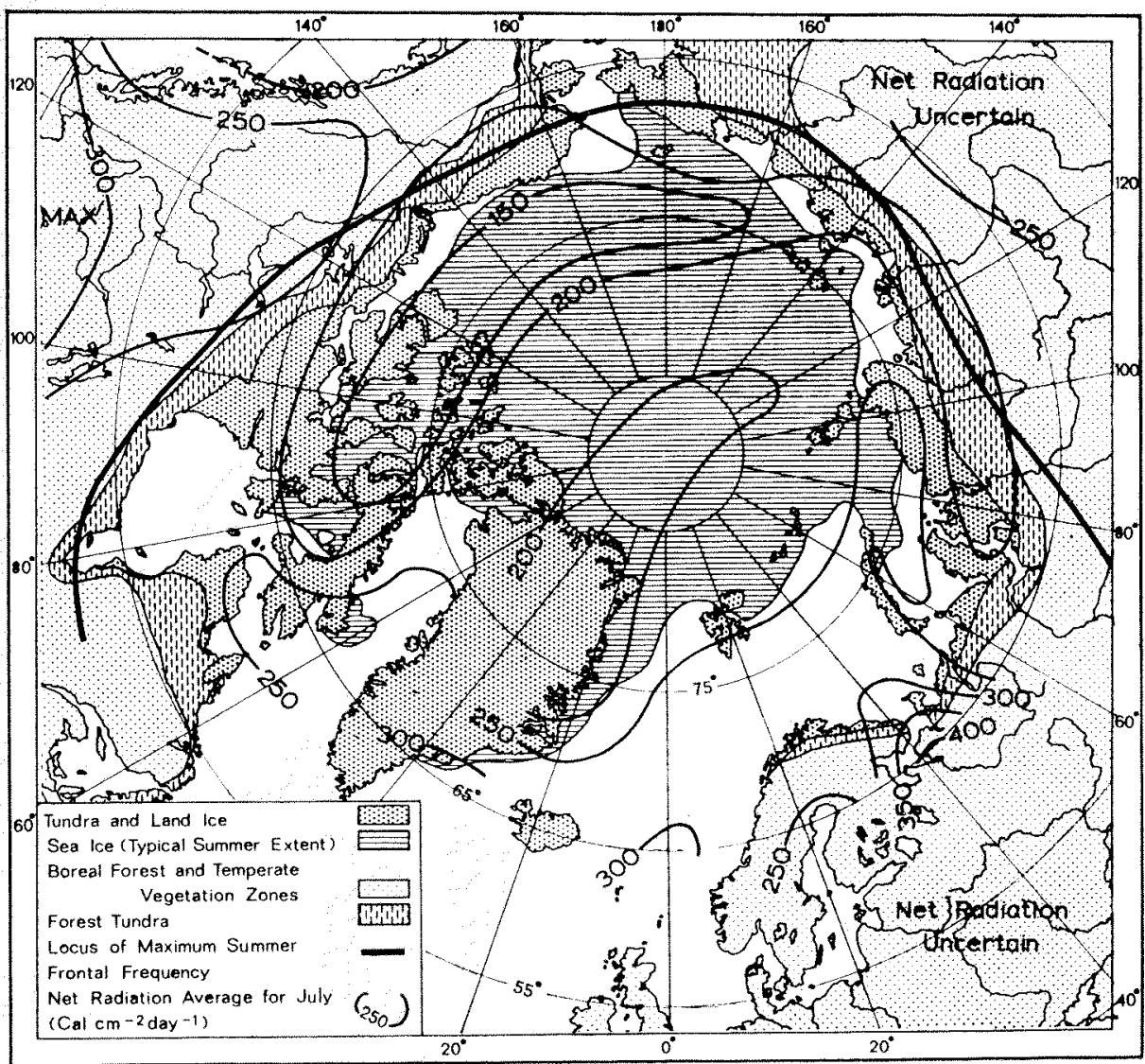

FIG. 3. Axis of Reed-Kunkel (1960) maximum of summer frontal activity in relation to estimated net radiation $\left(1 \mathrm{yday}^{-1}\right)$ for July.

The arctic jet seems to be baroclinically unstable, and is affected throughout the year by eastward-moving cyclone waves. These produce most of the warmseason rains in subarctic and arctic land areas, including Siberia and Alaska. In winter they are mainly features of subarctic Canada and western Siberia, but the "western disturbances" of north and central China belong in the same family. Along the Atlantic flank of the Arctic, deep occluded cyclones often penetrate via the Norwegian and Barents Seas, and may persist as cold lows within the arctic core for long periods. We have thus learned to think of the Arctic as a cyclonically dominated area, though the low humidities of the air-streams involved reduce 
the associated cloudiness and precipitation. Anticyclones do, of course, occur, and along certain paths - notably southeastwards across Canada and east Asia - regularly move out of the Arctic into the main westerly belt. Only in spring do they dominate the surface weather map over the high Arctic, however.

I shall not discuss the more familiar aspects of the tropospheric climate - the properties of arctic air, the arctic inversion, precipitation distribution and other features; the past fifteen years have not radically altered our knowledge of these things.

\section{THE STRATOSPHERE AND MESOPHERE}

Above $15 \mathrm{~km}$. the Arctic is the core of a seasonally reversing circumpolar vortex seemingly distinct from the tropospheric westerlies. In summer, from May until mid-August, light easterlies blow along almost circular paths around a warm Arctic whose high temperatures trace back to absorption of the continuous solar irradiation by ozone. In high latitudes these easterlies are almost undisturbed, though in mid-latitudes westward-drifting troughs and ridges affect the flow (Muench 1968). The easterlies extend to above the warm stratopause at about $50 \mathrm{~km}$. where arctic temperatures are above $0^{\circ} \mathrm{C}$. The base of the easterlies is near $15 \mathrm{~km}$. over the arctic ocean coasts, and at about $23 \mathrm{~km}$. in mid-latitudes (Hare 1960).

This régime reverses gradually between mid-August and late September; progressive cooling of the entire stratospheric column creates westerly flow around a centre near the pole, which links downwards with the tropospheric westerlies. During October and November cooling intensifies in the darkening polar stratosphere, and the westerlies of winter become more baroclinic and much stronger; over Alaska, the Bering Sea and adjacent regions of Siberia, however, the cooling ceases, and the stratosphere becomes and usually remains warm for the rest of winter. This creates a powerful stratospheric ridge over or west of Alaska (Boville 1960) which is one of the startling discoveries of the past fifteen years.

The Alaskan ridge deforms the stratospheric polar-night westerlies up to at least $55 \mathrm{~km}$., as rocket evidence shows (Teweles 1965; Frith 1968). The westerlies constitute a cold-cored vortex centred in the mean between Svalbard and Cape Chelyuskin (Fig. 4). Temperatures are near $-80^{\circ} \mathrm{C}$. at the centre in the 25-30 km. layer, but the stratopause at about $50 \mathrm{~km}$. is believed still to be warm even in mid-winter (Murgatroyd et al. 1965). Intensely baroclinic westerlies surround the centre, maximum temperature gradients being over northern Alaska.

Like its westerly counterpart in the troposphere, this higher-level system of the arctic winter is highly disturbed, but neither the overall dynamics nor the character of the disturbances is fully understood. The layer between 15 and 45 $\mathrm{km}$. (and probably higher) is subject to spectacular temperature changes, especially sudden warmings that may raise temperatures $30^{\circ} \mathrm{C}$. or more in a day. These changes necessarily involve major wind changes at all levels. Originally an extraterrestrial radiative source was suspected (Scherhag 1952), but it now seems certain that subsidence (or uplift) of the order of less than $5 \mathrm{~km}$. per day can account for the observed changes of temperature and kinetic energy. 


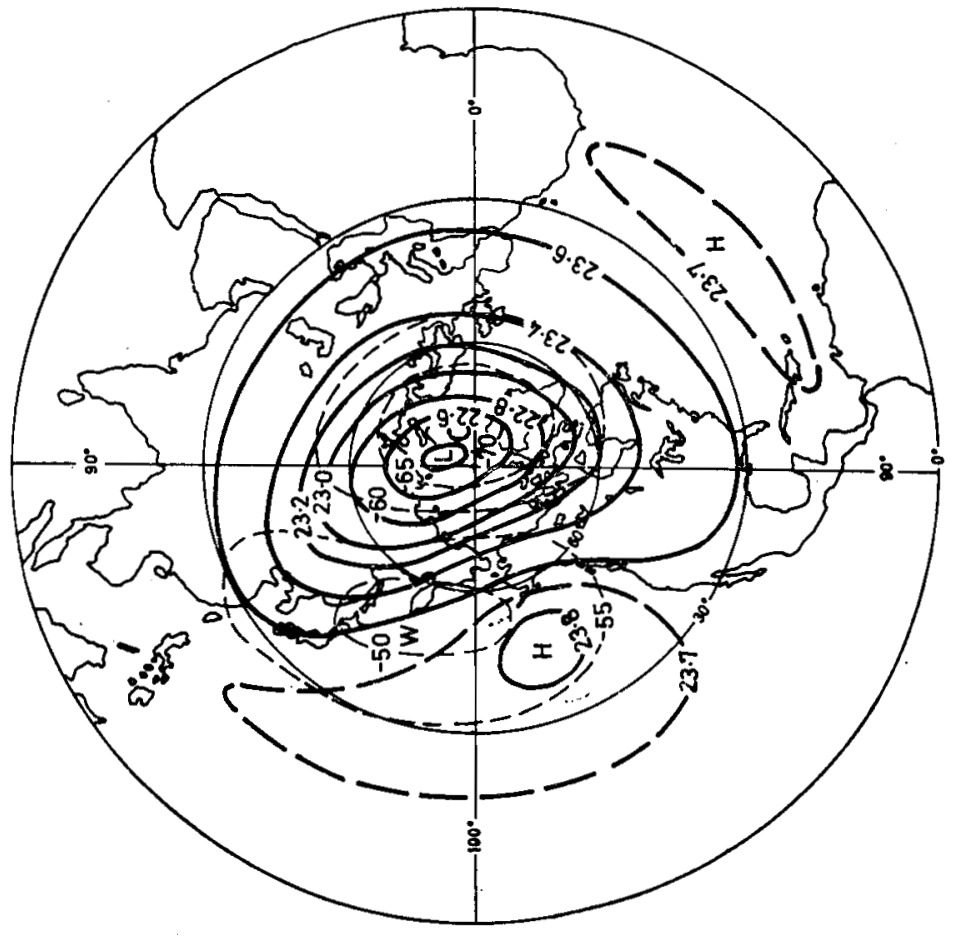

.5

范

온

?ี

菊

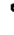

.

急需 点

놀

$\stackrel{5}{*}$

홍

.

bi

品

긍

苟。
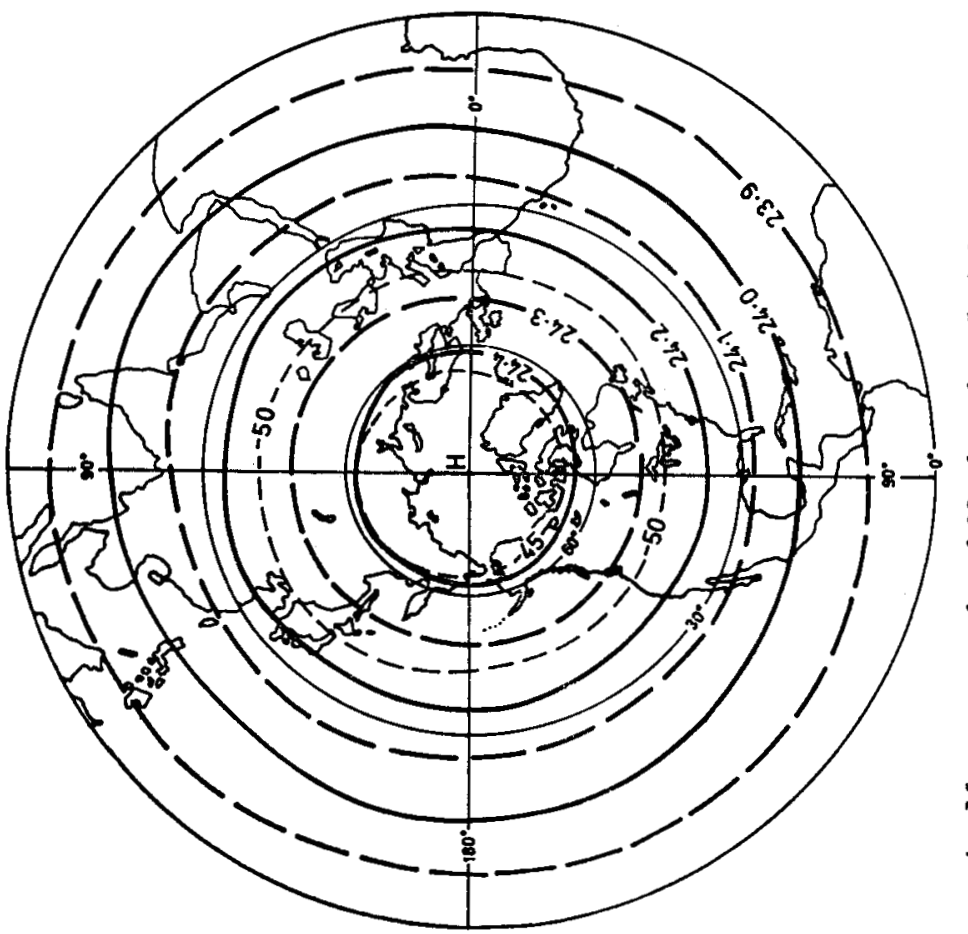

害.

흔.

ह

릉

\&

密

올

일

4

를

苟 
These events show themselves dynamically as large changes in the eccentricity or disturbances of wave numbers 2 and 3 that contribute most of the wave energy at these levels (Fig. 5). Occasionally shorter troughs (of wave number 4 or 5) appear to amplify over arctic Canada, east of the intense Alaskan baroclinity, and these have been interpreted as baroclinically unstable systems generating kinetic energy (Boville et al. 1961). In general, however, it appears to be very likely that the energetics at these levels depends on events at lower levels, and is not usually self-generated.
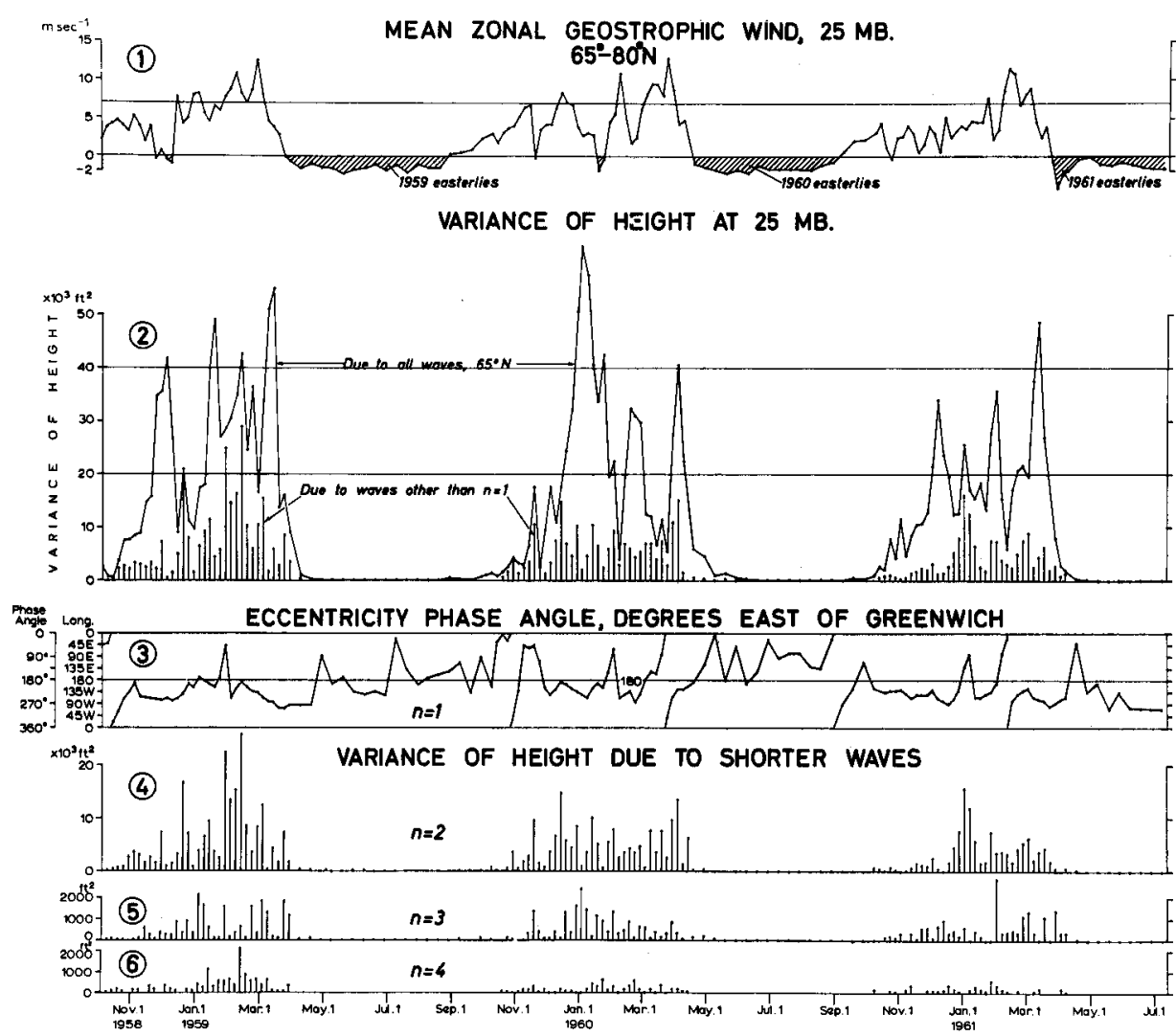

FIG. 5. Wave climatology for $25-\mathrm{mb}$ surface along $65^{\circ} \mathrm{N}, 1958-61$. The variance of height, resolved by wave number, shows how the disturbance energy was distributed through three years of stratospheric history. The summer easterlies were undisturbed.

The westerly vortex collapses spectacularly at the end of winter, with the final warming episode (Wilson and Godson 1963). This consists of one or two centres of subsidence that rapidly break up the system. For a few weeks the stratosphere and mesosphere have rather disorganized flow, but by early or mid-May easterlies are re-established through most of the column, and are completely dominant for the rest of summer. The spectacular dynamical warming that precedes this régime comes at widely variable dates, and cannot be ascribed to renewed solar warming of the ozone layer. 
The composition of the lower stratosphere reflects these processes. In the layer of 12 to $25 \mathrm{~km}$., but especially in that of 16 to $18 \mathrm{~km}$., the thermal structure is remarkable for the existence in northern mid-latitudes of the stratospheric warm belt. This separates the deep, cold, tropical tropopause belt from the cold north polar cap, except for about three summer months. The air of this stratospheric warm belt is believed to be excessively dry, with frost points of about $-80^{\circ} \mathrm{C}$. (approximately the temperature of the tropical tropopause). In the late winter and spring it also appears to be invaded from time to time by high ozone-content air, presumably introduced by subsidence in association with the stratospheric disturbances just described. It has been shown that some of the short-period fluctuations in total ozone in the air column reflect the motion of stratospheric disturbances (Allington et al. 1960; Boville and Hare 1961), and the spring maximum of ozone similarly relates to the final warming episode (Godson 1960; Hering and Borden 1964).

\section{DISCUSSION}

I hope that I have been able to show that we have now a good picture of the annual pattern of events in the high latitude circulation up to the stratopause and basal mesosphere. Most of the theoretical questions raised by the discoveries of the past fifteen years are, however, still open. Among these I would isolate the following as worthy of much further work:

1) The relationship between the circulation within the tropospheric arctic core and the rest of the general circulation is still imperfectly understood. Most general circulation numerical experiments are based on realistic assumptions about the westerly belt, and tend to generate a single baroclinic westerly current. Experience in high-latitude analysis, however, suggests that multiple baroclinity and jet-structure may be typical of the circumpolar vortex, and that the arctic front and jet must arise from hemispheric patterns of heating and cooling, rather than from local frontogenesis. An adequate theory of the general circulation must explain the existence of this structure.

2) The dynamics and energetics of the polar night westerly vortex require further analysis, as does its interaction with the tropospheric westerlies beneath. That such interaction must occur, and must be critical to the behaviour of the upper level vortex, is intuitively probable, and theoretically predicted by Charney and Drazin (1961) and Charney and Stern (1962). Proof of such interactions depends on sophisticated forms of spectral analysis. Recent studies by Muench (1965), Perry (1966), Byron-Scott (1967), and Paulin (1968) have begun to establish the form of the connections, and to relate it to theory; but much remains to be done, particularly as regards the origins of the quasi-permanent Alaskan ridge.

3) Finally, the entire question of eddy and radiative transfer processes on all scales requires attention at stratospheric levels. The problem of the existence of the stratosphere, and of the overlying mesosphere, is still one depending on the radiative balance and its interaction with the circulation. And the problems caused by its curious composition - dryness, ozone richness, aerosol distribution - are 
equally to be approached from both the dynamical standpoint of this paper and the standpoint of exchange processes for mass and energy, with which I have not dealt.

In all these problems high latitude conditions are of major interest. Hence it is very suitable that I should end by wishing the new facilities of NARL all success. I hope that the scientists who use it will be conscious of the remarkable things going on over their heads.

\section{REFERENCES}

ALlingtoN, K., B. W. Boville and F. K. HARE. 1960. Midwinter ozone variations and stratospheric flow over Canada, 1958-59. Tellus, 12: 266-73.

BovILlE, B. W. 1960. The Aleutian stratospheric anticyclone. Journal of Meteorology, 17: 329-36.

BOVILLE, B. W. and F. K. HARE. 1961. Total ozone and perturbations in the middle stratosphere. Quarterly Journal of the Royal Meteorological Society, 87: 490-501.

Boville, B. W., C. V. WILson and F. K. HARE. 1961. Baroclinic waves of the polar-night vortex. Journal of Meteorology, 18: 567-80.

BRYSON, R. A. 1966. Air masses, streamlines and the Boreal Forest. Geographical Bulletin, 8: 228-69.

BYRON-SCOTT, R. 1967. A stratospheric general circulation experiment. McGill University, Arctic Meteorology Research Group, Publications in Meteorology, 87. 201 pp., with appendices.

CHARNEY, J. G. and P. G. DRAZIN. 1961. Propagation of planetary scale disturbances from the lower into the upper atmosphere. Journal of Geophysical Research, 66: 83-109.

CHARNEY, J. G. and M. E. STERN. 1962. On the stability of internal baroclinic jets in a rotating atmosphere. Journal of Atmospheric Sciences, 19: 159-72.

FlohN, H. 1952. Zur Aerologie der Polargebiete. Meteorologisches Rundschau, 5: 81-87 and 121-28.

FRITH, R. 1968. The earth's higher atmosphere. Weather, 23: 142-55.

GoDson, w. L. 1960. Total ozone and the middle stratosphere over arctic and sub-arctic areas in winter and spring. Quarterly Journal of the Royal Meteorological Society, 86: 30117.

HARE, F. K. 1960 . The summer circulation of the arctic stratosphere below $30 \mathrm{~km}$. Quarterly Journal of the Royal Meteorological Society, 86: 127-43.

59.

1968. The arctic. Quarterly Journal of the Royal Meteorological Society, 94:439-

HARE, F. X. and B. W. BOVILLE. 1965. The polar circulations. In: Murgatroyd et al. pp. 43-78 (see below).

HERING, W. S. and T. R. BORDEN, JR. 1964. Ozonesonde observations over North America, Vol. 2. Air Force Cambridge Research Laboratories, U.S.A.F., Environmental Research Papers, 38.280 pp.

MUENCH, H. S. 1965. Stratospheric energy processes and associated atmospheric long-wave structure in winter. Air Force Cambridge Research Laboratories, U.S.A.F. Environmental Research Papers, 95.73 pp.

1968. Large-scale disturbances in the summertime stratosphere. Journal of Atmospheric Sciences, 25: 1108-115. 
MURgatroyd, R. J., F. K. HARE, B. W. Boville, S. TEWEles and A. Kochanski. 1965. The circulation in the stratosphere mesosphere and lower thermosphere. World Meteorological Organization Technical Notes, 70.206 pp.

PAUlIN, G. 1968. Spectral atmospheric energetics during January 1959. McGill University, Arctic Meteorology Research Group, Publications in Meteorology, $91.256 \mathrm{pp}$.

PERRY, J. S. 1967. Long-wave energy processes in the 1963 sudden stratospheric warming. Journal of Atmospheric Sciences, 24: 539-50.

REED, R. J. and B. A. KUNKEL. 1960. The arctic circulation in summer. Journal of Meteorology, $17: 489-506$.

SCHERHAG, R. 1952. Die explosionsartigen Stratosphärenerwärmungen des Spätwinters 1951-52. In: Weickmann-Heft, Berichte des Deutschen Wetterdienstes in der US-Zone, Nr. 38, pp. 51-63.

TEWELES, s. 1965. Applications of meteorological rocket network data. In: Murgatroyd et al., pp. 79-106 (see above).

VAN MIEGHEM, J. 1961. Zonal harmonic analysis of the northern hemisphere geostrophic wind field. Paris: Union géodésique et géophysique internationale, Monographie 8. 57 pp.

WILSON, C. V, and W. L. GODSON. 1963. The structure of the arctic winter stratosphere over a 10-year period. Quarterly Journal of the Royal Meteorological Society, 89: 205-24. 